\title{
Novel silk fibroin/elastin wound dressings
}

\author{
Andreia Vasconcelos ${ }^{\mathrm{a}}$, Andreia C. Gomes ${ }^{\mathrm{b}}$, Artur Cavaco-Paulo ${ }^{\mathrm{a}, *}$ \\ ${ }^{a}$ Universidade do Minho, Departamento de Engenharia Têxtil, Campus de Azurém, 4800-058 Guimarães, Portugal \\ ${ }^{\mathrm{b}}$ Centre of Molecular and Environmental Biology (CBMA), Department of Biology, Campus de Gualtar, 4710-057 Braga, Portugal
}

\section{A R T I C L E I N F O}

\section{Article history:}

Received 28 October 2011

Received in revised form 12 April 2012

Accepted 20 April 2012

Available online 27 April 2012

\section{Keywords:}

Silk fibroin

Elastin

Scaffold

Wound dressing

Wound healing

\begin{abstract}
A B S T R A C T
Silk fibroin (SF) and elastin (EL) scaffolds were successfully produced for the first time for the treatment of burn wounds. The self-assembly properties of SF, together with the excellent chemical and mechanical stability and biocompatibility, were combined with elastin protein to produce scaffolds with the ability to mimic the extracellular matrix (ECM). Porous scaffolds were obtained by lyophilization and were further crosslinked with genipin (GE). Genipin crosslinking induces the conformational transition from random coil to $\beta$-sheet of SF chains, yielding scaffolds with smaller pore size and reduced swelling ratios, degradation and release rates. All results indicated that the composition of the scaffolds had a significant effect on their physical properties, and that can easily be tuned to obtain scaffolds suitable for biological applications. Wound healing was assessed through the use of human full-thickness skin equivalents (EpidermFT). Standardized burn wounds were induced by a cautery and the best re-epithelialization and the fastest wound closure was obtained in wounds treated with 50SF scaffolds; these contain the highest amount of elastin after 6 days of healing in comparison with other dressings and controls. The cytocompatibility demonstrated with human skin fibroblasts together with the healing improvement make these SF/EL scaffolds suitable for wound dressing applications.
\end{abstract}

(C) 2012 Acta Materialia Inc. Published by Elsevier Ltd. All rights reserved.

\section{Introduction}

Skin wounds are the disruption of normal skin physiology. From the moment the wound is created, the healing mechanism is initiated to re-establish skin continuity. The healing process is complex and involves an integrate response of different cell types and growth factors [1-5]. Promotion of healing is often accompanied by the use of biocompatible wound dressings: these should promote a moist environment in the wound and serve as a shield against external factors like dust and bacteria; enhance water and vapor permeation and promote epithelialization by releasing biological agents to the wounds. Due to its unique properties of high mechanical strength and excellent biocompatibility, silk fibroin has been explored for the development of wound dressings. The degradation rates of electrospun silk materials applied as wound dressings have been evaluated [6] and the incorporation of growth factors into electrospun silk mats has been shown to accelerate wound healing [7]. Moreover, silk films have been shown to heal full thickness skin wounds in rats faster than traditional porcine-based wound dressings [8].

Blending silk fibroin with other components has been shown to improve the properties of the resulting material. This allows the modulation of biodegradation and release rates, important

\footnotetext{
* Corresponding author. Tel.: +351 2535 10100; fax: +351 253510293 .

E-mail address: artur@det.uminho.pt (A. Cavaco-Paulo).
}

parameters in the biomaterials field. Recently, we developed silk fibroin/keratin films incorporating a synthetic inhibitor of elastase, to control the high levels of this enzyme produced in a chronic wound environment [9]. Silk fibroin/alginate sponges demonstrate a higher healing effect than both components acting alone [10]. In this work, scaffolds based on silk fibroin and soluble elastin were developed and tested.

Elastin (EL) is an insoluble extracellular matrix protein that provides elasticity and resilience to the arteries, lungs and skin [11-13]. Due to its highly crosslinked nature, elastin is highly insoluble and difficult to process into new biomaterials. As a consequence, soluble forms of elastin including tropoelastin [14], $\alpha$-elastin [15,16] and elastin-like polypeptides [17-19] are frequently used to develop elastin-based biomaterials. Nevertheless, a crosslinking step is required to obtain an insoluble material. There are several crosslinking methods for elastin including chemical $[14,15,20]$, enzymatic [21], physical $[16,22-24]$ and $\gamma$-irradiation [25]. Among them, chemical crosslinking agents are widely used. Aldehydes and epoxy compounds have been commonly used in biomaterial constructs due to their efficient formation of crosslinks with amino acid side chains, low antigenicity and sufficient mechanical strength. Despite these advantages, they exhibit high cytotoxicity $[20,26,27]$.

Genipin (Ge) is a natural covalent crosslink agent isolated from the fruits of Gardenia jasminoides Ellis [28] that offers comparable crosslinking efficacy. It has been reported that genipin binds with 
biological tissues [29,30] and biopolymers [31,32], leading to matrices with good mechanical properties, reduced swelling extent and significantly reduced cytotoxicity when compared to synthetic crosslink agents like glutaraldehyde and epoxy compounds [31,33].

To our knowledge, elastin has been crosslinked with collagen [34,35], fibrin [36,37] and gelatin [34,38] for the development of biomaterials, but never with silk fibroin. In this study, we developed silk fibroin/elastin (SF/EL) scaffolds crosslinked with genipin. The resulting materials were characterized by their physicalchemical properties and the effect of crosslinking on those properties was evaluated. Moreover, the wound dressing functionality of these materials was tested with a real chronic wound exudate and the healing ability was assessed through the use of three-dimensional (3-D) human skin equivalents.

\section{Materials and methods}

\subsection{Materials}

Silk cocoons from Bombyx mori were kindly supplied from "Sezione Specializzata per la Bachicoltura" (Padova). Elastin soluble from bovine neck ligament was purchased from Sigma (Spain). Genipin is a product of Wako Chemicals (Germany). The BJ5ta cell line (telomerase-immortalized human normal skin fibroblasts) was purchased from ATCC through LGC Standards.

Human full-thickness skin equivalents (EpidermFT) were supplied by MatTek Corporation (USA). All other reagents, including those used in cell culture, were analytical grade and purchased from Sigma (Spain).

\subsection{Preparation of silk fibroin solution}

Silk was purified from its sericin content as previously described [9,39-42]. The cocoons were cut, cleaned from debris and larvae and autoclaved for $30 \mathrm{~min}$ at $120^{\circ} \mathrm{C}$. Fibroin was then thoroughly washed with distilled water and dried overnight at room temperature. Silk fibroin (SF) solution $(2 \%(\mathrm{w} / \mathrm{v}))$ was prepared by dissolving fibroin in $9.6 \mathrm{M} \mathrm{LiBr}$ solution at $60^{\circ} \mathrm{C}$ for $3 \mathrm{~h}$. The resulting solution was filtered, and dialyzed against distilled water until salts were completely removed, using cellulose tubing (Sigma, Spain) (molecular-weight cut-off of 12,000-14,000 Da).

\subsection{Silk fibroin/elastin blends preparation; crosslinking reaction; scaffold formation}

Elastin (EL) solution was prepared by dissolving the elastin powder in distilled water. SF $(2 \%)$ and EL (1\%) were mixed to prepare blends of 100/0 SF/EL, 80/20 SF/EL and 50/50 SF/EL. Genipin (GE) powder, 0.1 and $0.5 \%(\mathrm{w} / \mathrm{v})$ was added to blend solutions under constant stirring at room temperature until complete dissolution of GE powder. The crosslinking reaction was carried out for 3,6 and $24 \mathrm{~h}$ at $37^{\circ} \mathrm{C}$. The resulting solutions were cast on 96-well plates and frozen at $-20^{\circ} \mathrm{C}$ for 2 days and freeze dried for 2 days to remove the solvent completely. SF/EL scaffolds without genipin were used as controls and were prepared by the same process described above. The control samples were identified as 100SF, 80SF and 50SF, which correspond to 0,20 and $50 \%$ of elastin, and crosslinked scaffolds were identified as 100SFyGE, 80SFyGE and 50SFyGE, where y is the genipin concentration used. In order to induce the transition of SF from random coil to $\beta$-sheet structure and consequently insolubility, scaffolds were immersed in $90 \%(\mathrm{v} / \mathrm{v})$ methanol solution for $30 \mathrm{~min}$ and then washed in distilled water and air dried.

\subsection{Degree of crosslinking}

The crosslinking degree was determined by the ninhydrin assay [40-42]. Samples $(6.0 \pm 0.7 \mathrm{mg})$ were heated with a ninhydrin solution $(2 \%(\mathrm{w} / \mathrm{v}))$ at $100{ }^{\circ} \mathrm{C}$ for $20 \mathrm{~min}$. The optical absorbance of the resulting solution was recorded at a wavelength of $570 \mathrm{~nm}$ using a He $\lambda$ ios $\gamma$ ThermoSpectronic spectrophotometer. The amount of free amino groups in the test sample after heating with ninhydrin is proportional to the optical absorbance of the solution. The concentration of free $\mathrm{NH}_{2}$ groups in the sample was determined from a standard curve of glycine concentration vs. absorbance. SF/EL scaffolds prepared without genipin were used as control materials. Triplicate samples were evaluated. The degree of crosslinking was determined by the following equation:

Degree of crosslinking $(\%)=\frac{\left[\left(\mathrm{NH}_{2}\right)_{n c}-\left(\mathrm{NH}_{2}\right)_{c}\right]}{\left(\mathrm{NH}_{2}\right)_{n c}} \times 100$

$\left(\mathrm{NH}_{2}\right)_{\mathrm{nc}}$ and $\left(\mathrm{NH}_{2}\right)_{\mathrm{c}}$ are, respectively, the mole fraction of free $\mathrm{NH}_{2}$ in non-crosslinked and crosslinked samples.

\subsection{FTIR spectroscopy}

FTIR spectra of pure SF and SF/EL scaffolds were measured with a Perkin-Elmer (Spectrum One FTIR) spectrometer in the spectral region of $4000-650 \mathrm{~cm}^{-1}$ with a ZnSe ATR cell. Spectra were acquired for sponges with and without methanol treatment. For EL samples, FTIR spectra were recorded in $\mathrm{KBr}$ pellets using a FTIR4100 from Jasco with a resolution of $2 \mathrm{~cm}^{-1}$.

\subsection{Thermal analysis}

Differential scanning calorimetry (DSC) measurements were performed with a DSC-30 instrument (MettlerToledo), from room temperature to $120^{\circ} \mathrm{C}$, at a heating rate of $10^{\circ} \mathrm{C} \mathrm{min}^{-1}$, and kept at $120^{\circ} \mathrm{C}$ for $10 \mathrm{~min}$, to induce dehydration of samples. The temperature was lowered to room temperature and increased to $500{ }^{\circ} \mathrm{C}$ at a heating rate of $10{ }^{\circ} \mathrm{C} \mathrm{min}^{-1}$. Sample weight was 2-3 mg. The open aluminum cell was swept with $\mathrm{N}_{2}$ during the analysis. The analysis was performed in duplicate for scaffolds with and without methanol treatment.

\subsection{Scanning electron microscopy (SEM)}

Cross-sections were prepared by cutting the SF/EL scaffolds with a razor blade in liquid nitrogen. Before analysis, the scaffolds were coated with gold and examined morphologically using a NOVA Nano SEM 200 FEI. The morphology was determined before and after methanol treatment.

\subsection{Swelling ratio}

SF/EL scaffolds, treated with methanol and completely dry $\left(60{ }^{\circ} \mathrm{C}\right.$ for $24 \mathrm{~h}$ ) were immersed in phosphate-buffered saline (PBS; pH 3.0, 7.4 and 11 ) at $37^{\circ} \mathrm{C}$ for $24 \mathrm{~h}$. The excess buffer was removed and the wet weight of the scaffolds was determined. The swelling ratio of the film was calculated as follows:

Swelling ratio $=\frac{W_{S}-W_{d}}{W_{d}}$

$W_{S}$ is the mass of the swollen material and $W_{d}$ is the initial dry mass. 


\subsection{Porosity}

The porosity of the SF/EL scaffolds with different blending ratios was measured by the liquid displacement method [43]. Hexane was used as the displacement liquid because it is a non-solvent for SF. The scaffolds were immersed in a known volume (V1) of hexane in a graduated cylinder for $30 \mathrm{~min}$. The total volume of hexane after impregnation into the scaffold was recorded as V2. The impregnated scaffolds were then removed from the cylinder and the residual hexane volume was recorded as V3. For all types of scaffolds, experiments were carried out in triplicate. Data are presented as average \pm SD. One-way ANOVA analysis of variance with Bonferroni post-tests was performed, with statistically significant differences when $p<0.001$. All calculations were performed using GraphPad software (version 5.03). The porosity of the scaffold $(\varepsilon)$ was calculated by the following equation:

$\varepsilon(\%)=\frac{V_{1}-V_{3}}{V_{2}-V_{3}} \times 100$

\subsection{In vitro degradation}

\subsubsection{Porcine pancreatic elastase (PPE)}

SF/El scaffolds previously treated with methanol, with and without crosslinking, were incubated for 21 days at $37{ }^{\circ} \mathrm{C}$ in a solution containing $0.1 \mathrm{mg} \mathrm{ml}^{-1}$ of PPE in $100 \mathrm{mM}$ Tris- $\mathrm{HCl}$ buffer, $\mathrm{pH}$ 8.0. The control samples were incubated in PBS buffer solution ( $\mathrm{pH}$ 7.4) without enzyme and submitted to the same conditions. The solutions were replaced every $24 \mathrm{~h}$.

\subsubsection{Wound exudate}

Wound exudate was collected from pressure wounds using a vacuum assisted closure system. Wound fluid was diluted ten-fold in PBS solution and centrifuged to remove cells and tissue material. SF/EL scaffolds were incubated with exudate in the same conditions described above in a fixed ratio of exudate per mg of scaffold of $6 \mathrm{mg} \mathrm{ml}^{-1}$. At designated time points, samples were washed thoroughly with distilled water, dried in a desiccator and weighted to estimate the extent of degradation by the following equation:

Weight loss $(\%)=\frac{m_{0}-m_{f}}{m_{0}} \times 100$

$m_{0}$ and $m_{f}$ are respectively, the initial and final dry mass of the scaffold.

\subsection{In vitro release}

The release of a compound from SF/EL scaffolds was examined by the incorporation of an antibacterial agent, gentamicin $\left(2 \mathrm{mg} \mathrm{ml}^{-1}\right)$. For control samples, gentamicin was dissolved in the protein solutions and stirred for $5 \mathrm{~min}$ at room temperature. The resulting solutions were cast in 96 -well plates to prepare the $\mathrm{SF} / \mathrm{EL}$ scaffolds. In the case of crosslinked samples, gentamicin was dissolved in the protein solution before crosslinking reaction. Before release studies, control and crosslinked scaffolds were treated with methanol. SF/EL scaffolds were incubated at $37^{\circ} \mathrm{C}$ in PBS buffer and in a solution containing $0.1 \mathrm{mg} \mathrm{ml}^{-1}$ of PPE. Solutions were changed every $24 \mathrm{~h}$. At determined time points, aliquots were taken and gentamicin release was determined using the 0 -phthaldialdehyde method [44]. The analysis was carried out by measuring the maximum fluorescence of gentamicin-o-phthaldialdehyde complex using a multiplate reader (Synergy HT W/TRF from BioTek) in the fluorescence mode at an emission wavelength of $456 \mathrm{~nm}$. After each measurement, the samples were added back to the medium to restore the equilibrium conditions. The quantification of the release was established by a gentamicin standard curve. Release studies were performed in triplicate samples and for a period of 7 days. The release behavior of compounds from polymeric systems can be determined by fitting the release data to the empirical relationship given by the Ritger-Peppas equation [45]:

$\frac{M_{t}}{M_{\infty}}=k t^{n}$

$M_{t} / M_{\infty}$ is the fractional drug release at time $t ; t$ is the release time; $k$ is the kinetic constant that measures the drug release rate, and $n$ is the diffusion exponent that depends on the release mechanism and the geometry of the matrix. To determine $n$ values, Eq. (4) is modified in Eq. (5) and $n$ is determined from the slope of the plot of $\log$ (\%released) vs. $\log t$.

$\log (\%$ released $)=\log \left(M_{t} / M_{\infty}\right)=\log k+n \log t$

\subsection{Cytotoxicity}

The scaffolds were tested for cytotoxicity according to ISO standards $(10993-5,2009)$. The BJ5ta cell line (normal human skin fibroblasts) was maintained according to ATCC recommendations (four parts Dulbecco's modified Eagle's medium (DMEM) containing $4 \mathrm{mM}$ L-glutamine, $4.5 \mathrm{~g} \mathrm{l}^{-1}$ glucose, $1.5 \mathrm{~g} \mathrm{l}^{-1}$ sodium bicarbonate, and one part of Medium 199, supplemented with $10 \%(\mathrm{v} / \mathrm{v})$ of fetal bovine serum (FBS), 1\% (v/v) of penicillin/streptomycin solution and $10 \mu \mathrm{g} \mathrm{ml}^{-1}$ hygromycin $\mathrm{B}$ ). The cells were maintained at $37{ }^{\circ} \mathrm{C}$ in a humidified atmosphere of $5 \% \mathrm{CO}_{2}$. Culture medium was refreshed every 2 to 3 days.

\subsubsection{Test by indirect contact}

Scaffolds ( $\varnothing=3 \mathrm{~mm}$ and $6 \mathrm{~mm}$ thickness) were sterilized by immersion in ethanol $70 \%$ for $30 \mathrm{~min}$, then hydrated and thoroughly rinsed with PBS. The conditioned media were obtained by incubating the sponges in $1 \mathrm{ml}$ of DMEM in a $\mathrm{CO}_{2}$ incubator at $37^{\circ} \mathrm{C}$ for 5 days. The sponges were then removed and the conditioned media were obtained. Before use, the conditioned media were filtered to remove degraded scaffolds and diluted if necessary in complete cell culture medium. Complete cell culture medium subjected to the same conditions but not exposed to the sponges was used as a negative control, whereas a $1 \%(\mathrm{v} / \mathrm{v})$ solution of Triton ${ }^{\circledR} \mathrm{X}-100$ (Sigma) prepared in fresh culture medium was used as a toxicity positive control. Cells were seeded at a density of $20 \times 10^{3}$ cells $/ 100 \mu \mathrm{l} /$ well on 96 -well tissue culture polystyrene (TCPS) plates (TPP, Switzerland) the day before experiments and then incubated with the conditioned media. At each defined time point $(24,48$ and $72 \mathrm{~h})$, cell viability was assessed using the Alamar Blue assay (alamarBlue ${ }^{\circledR}$ Cell Viability Reagent, Invitrogen). Resazurin, the active ingredient of alamarBlue ${ }^{\circledR}$ reagent, is a non-toxic, cell-permeable compound that is blue in color and reduced to resorufin, red color compound, by viable cells. The quantity of resofurin formed is directly proportional to the number of viable cells. $10 \mu$ of alamarBlue ${ }^{\circledR}$ reagent was added to each well containing $100 \mu \mathrm{l}$ of culture medium. After $4 \mathrm{~h}$ of incubation at $37^{\circ} \mathrm{C}$ the absorbance at $570 \mathrm{~nm}$ was measured, using $600 \mathrm{~nm}$ as a reference wavelength, in a microplate reader (Spectramax 340PC). Data are presented as average \pm SD of two independent measurements. Two-way ANOVA with Bonferroni post-tests was performed, with statistically significant differences when $p<0.001$. All calculations were performed using GraphPad software (version 5.03).

\subsubsection{Cell proliferation}

Cell proliferation was determined in terms of DNA content to monitor the effect of the scaffolds on fibroblast. Scaffolds, prepared and sterilized as previously described $(\varnothing=15 \mathrm{~mm}$ and $3 \mathrm{~mm}$ thickness), were gently placed in 24-well (TCPS) plates (TPP, 
Switzerland), then $250 \mu$ l of cell suspension $\left(2 \times 10^{5}\right.$ cells ml $\left.{ }^{-1}\right)$ was loaded onto an upper side of each scaffold and allowed to infiltrate into the scaffold. The scaffolds were then incubated at $37^{\circ} \mathrm{C}$ under $5 \% \mathrm{CO}_{2}$ conditions for $3 \mathrm{~h}$ to allow for initial cell attachment. After the initial incubation period the wells were then filled with $250 \mu \mathrm{l}$ of medium and placed into a cell culture incubator and maintained at $37{ }^{\circ} \mathrm{C}$ with $5 \% \mathrm{CO}_{2}$ for either 3 or 5 days. Culture media were renewed every 2 days. After each indicated time interval, cells/scaffold constructs were collected, rinsed with PBS and cell proliferation was determined in terms of DNA content measured with Hoechst 33258 (Invitrogen). Briefly, cells were harvested from cell-scaffold constructs by incubating with a $0.25 \%$ solution of trypsin. Cells were then collected by centrifugation and lysed in a Tris- $\mathrm{HCl} 15 \mathrm{mM}$ pH 7.4 buffer with consecutive freeze-thaw cycles. Cell lysates were incubated with equal volume of $5 \mu \mathrm{g} \mathrm{ml}^{-1}$ Hoechest 33258 solution for $40 \mathrm{~min}$ at room temperature in the dark. Fluorescence was determined using a FLUOROSKAN ASCENT FL plate reader (ThermoScientific) at $350 \mathrm{~nm}$ excitation and $445 \mathrm{~nm}$ emission. The relative fluorescence unit value obtained from samples was interpolated against a DNA standard curve constructed using known number of cells, to determine the DNA content/number of cells in each sample. Data are presented as average \pm SD of two independent measurements. Two-way ANOVA with Bonferroni post-tests was performed, with statistically significant differences when $p<0.001$. All calculations were performed using GraphPad software (version 5.03).

\subsection{Wound healing assay}

Skin equivalents (EpidermFT) were cultured at the air-liquid interface in tissue culture inserts placed in six-well plates according to manufacturer's instructions. Upon receipt the tissues were placed into new six-well plates containing $2.5 \mathrm{ml}$ of fresh culture medium, supplied with the skin equivalents, and kept at $37^{\circ} \mathrm{C}$, $5 \% \mathrm{CO} 2$ overnight. Burn wounds were made by placing a cautery on top of the tissue for $10 \mathrm{~s}$. The SF/EL scaffolds were then placed over the wounded area. Two burn wounds per tissue were made to control wound size, and the healing was evaluated in two independent assays. Skin equivalents without dressing and treated with a commercial collagen dressing, Suprasorb C (Lohmann \& Rauscher, Germany), were used as controls.

Healing of these wounds was evaluated after 6 days by histological evaluation. Skin equivalents were fixed in $4 \%$ formaldehyde solution at room temperature. Subsequently, paraffin-embedded tissues section of $4 \mu \mathrm{m}$ thickness were obtained and stained with Haematoxylin and Eosin (H\&E). All sections were observed under a light inverted microscope (Olympus IX71).

\section{Results and discussion}

\subsection{Biochemical and biophysical properties of SF/EL scaffolds}

The formation of covalent bonds on blended systems may produce stable and ordered materials with beneficial effect on their properties. To achieve such effect, genipin was used to crosslink SF/EL scaffolds. Different crosslinking conditions were tested (Table 1). After $3 \mathrm{~h}$ of reaction a color change in the solutions is observed from light yellow to light blue, indicating the reaction between both SF and elastin with genipin. It is described that genipin reacts with amino acids or proteins to form dark blue pigments associated with the oxygen-radical polymerization of genipin $[30,32,46]$. After $6 \mathrm{~h}$ of reaction, the solutions became dark blue and the maximum crosslinking degree was reached.

The exact mechanism behind the interaction of genipin with both SF and elastin is yet to be fully described. The generally
Table 1

Degree of crosslinking obtained for SF/EL solutions, for the different reaction conditions, determined by Eq. (1).

\begin{tabular}{llll}
\hline \multirow{2}{*}{ Crosslinking treatment } & \multicolumn{3}{l}{ Degree of crosslinking $(\%)$} \\
\cline { 2 - 4 } & $100 \mathrm{SF}$ & $80 / 20 \mathrm{SF} / \mathrm{EL}$ & $50 / 50 \mathrm{SF} / \mathrm{EL}$ \\
\hline $3 \mathrm{~h} ; 0.1 \% \mathrm{GE}$ & $15.2 \pm 1.1$ & $18.4 \pm 1.5$ & $22.6 \pm 2.1$ \\
$6 \mathrm{~h} ; 0.1 \% \mathrm{GE}$ & $22.1 \pm 1.3$ & $29.3 \pm 1.1$ & $31.7 \pm 1.8$ \\
$24 \mathrm{~h} ; 0.1 \% \mathrm{GE}$ & $23.5 \pm 2.1$ & $30.2 \pm 1.5$ & $29.8 \pm 2.5$ \\
$3 \mathrm{~h} ; 0.5 \% \mathrm{GE}$ & $20.3 \pm 1.9$ & $24.2 \pm 1.1$ & $27.3 \pm 2.1$ \\
$6 \mathrm{~h} ; 0.5 \% \mathrm{GE}$ & $28.6 \pm 1.4$ & $48.3 \pm 2.2$ & $52.2 \pm 1.6$ \\
$24 \mathrm{~h} ; 0.5 \% \mathrm{GE}$ & $29.4 \pm 1.6$ & $46.7 \pm 1.3$ & $50.6 \pm 2.2$ \\
\hline
\end{tabular}

accepted mechanism is similar to that observed for amino-group containing compounds [32,47] where the ester groups of genipin interact with the amino groups of SF and elastin, leading to the formation of secondary amide linkages. Moreover, the amino groups initiate nucleophilic attacks which result in the opening of the genipin dihydropyran ring. An inherent phenomenon of genipin crosslinking is self-polymerization, which occurs by radical reaction of two amino-attached open rings [47,48]. Some authors [46] reported that genipin preferentially reacts with the amino acids lysine and arginine. SF and elastin contain respectively, $0.95 \%$ and $1.07 \%$ of these amino acids, which is a very low fraction. The crosslinking sites are thus low in number, which results in lower crosslinking degrees when compared with other genipin crosslinked blend systems [49]. The highest crosslinking degree obtained for sponges containing elastin might be related with the slightly higher fraction of lysine and arginine amino acids.

The genipin crosslinking of SF/EL scaffolds might induce conformational changes due to the structural rearrangement of chains to form covalent bonds. FTIR spectra of SF and elastin, with and without crosslinking, in the range of $600-2000 \mathrm{~cm}^{-1}$ are represented on Fig. 1. SF protein exists in three conformations namely random coil, Silk I ( $\alpha$-form) and Silk II ( $\beta$-sheet conformation). The 100SF spectrum (Fig. 1a) show bands at $1640 \mathrm{~cm}^{-1}$ for amide $\mathrm{I}(\mathrm{C}=\mathrm{O}$ stretching), $1517 \mathrm{~cm}^{-1}$ with a shoulder at $1532 \mathrm{~cm}^{-1}$ for amide II $(\mathrm{N}-\mathrm{H}$ deformation) and $1238 \mathrm{~cm}^{-1}$ for amide III (C-N stretching, $\mathrm{C}=\mathrm{O}$ bending vibration), indicating a random coil/Silk I conformation [50-53]. SF molecules can structurally rearrange due to changes in the hydrogen bonding by methanol treatment acquiring a $\beta$-sheet conformation. Genipin crosslinking is also able to induce $\beta$-sheet conformation of SF molecules. Comparing the SF spectra obtained after genipin crosslinking, it is clearly the transition from random coil to $\beta$-sheet conformation confirmed by the shifting to lower wavenumbers of amide I $\left(1620 \mathrm{~cm}^{-1}\right)$ and amide II $\left(1514 \mathrm{~cm}^{-1}\right)$ bands [50-53]. The shoulder observed at $1532 \mathrm{~cm}^{-1}$ for amide II assigned to random coil, progressively disappears with the increase in genipin concentration. Moreover, a characteristic band of genipin at $1105 \mathrm{~cm}^{-1}(-\mathrm{COH})$ appeared in the spectra of 100SF0.1GE and 100SF0.5GE, confirming once again the reaction between genipin and SF. The FTIR results evidenced that genipin crosslinking of SF is followed by protein conformational changes already shown by other authors [42,49]. Fig. 1b shows the spectrum for elastin protein that was acquired in powder form using $\mathrm{KBr}$ pellets. 100EL spectrum shows characteristic protein bands at 1651 (amide I), 1537 (amide II) and $1239 \mathrm{~cm}^{-1}$ (amide III), assigned to random coil conformation [54-56]. It can be seen that genipin induces in elastin structural changes into a more $\beta$-sheet conformation. This was confirmed by the shifting to lower wavenumbers of the amide I band. In addition, the appearance of a new peak at $1104 \mathrm{~cm}^{-1}$ and $1113 \mathrm{~cm}^{-1}$, characteristic of genipin, confirms the crosslinking reaction. The intensity of this peak is directly proportional to the amount of genipin used for the crosslinking. The results obtained after methanol treatment of the 

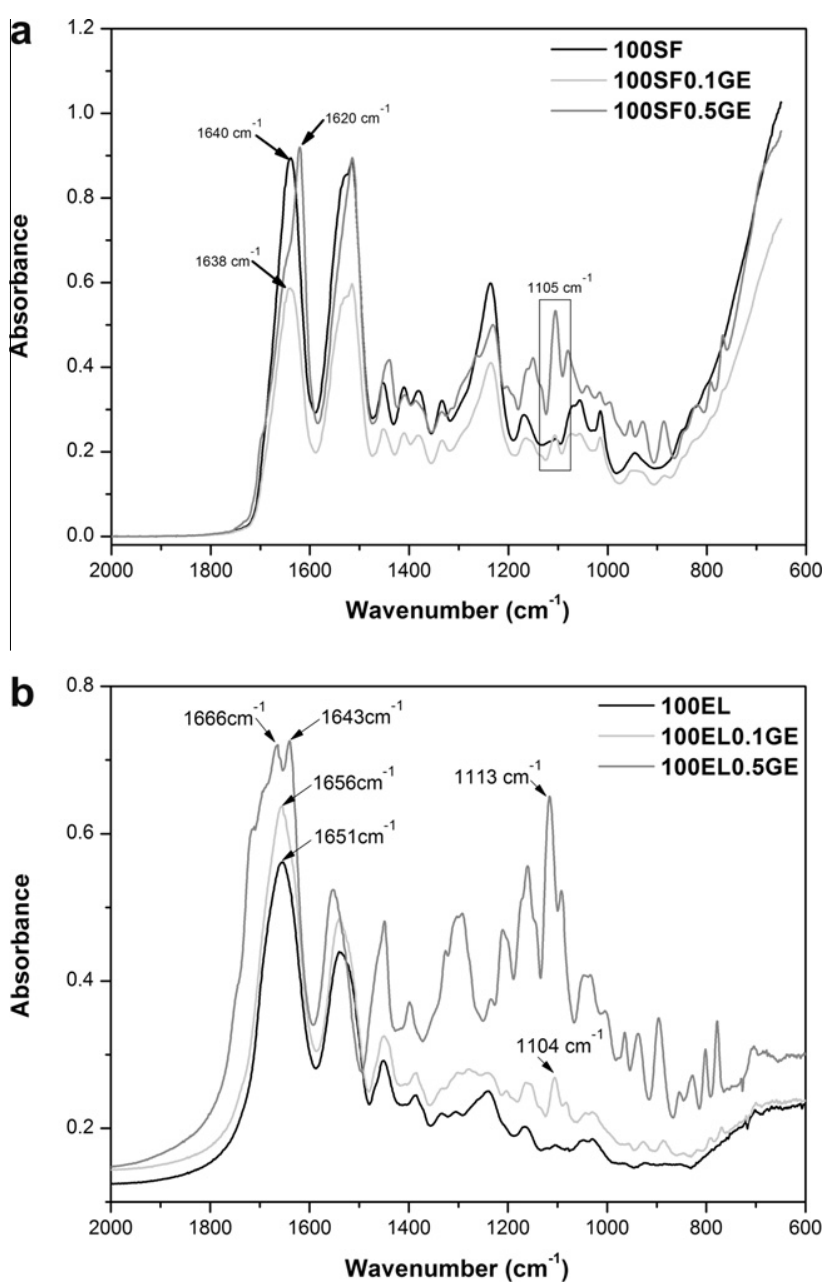

Fig. 1. FTIR absorbance spectra (a) of pure silk fibroin (100SF) and (b) pure elastin (100EL) and crosslinked with genipin (100X0.1GE and 100X0.5GE, where X is SF or EL).

scaffolds (Data not shown) show no additional changes, for both proteins, when compared with genipin crosslinked spectra.

FTIR spectra of blend systems show slightly changes of the wavenumbers and on the areas of the bands due to mixing effects of SF with elastin. The areas under the peaks for pure and blend systems were calculated by integration, and the ratio $A_{\mathrm{N}-\mathrm{H}}$ (area of $\mathrm{N}-\mathrm{H}$ bending, amide II) to $A_{\mathrm{C}=\mathrm{O}}$ (area of $\mathrm{C}=\mathrm{O}$ stretching, amide I) (data not shown). It was shown that the addition of elastin decrease the ratio of $A_{\mathrm{N}-\mathrm{H}} / A_{\mathrm{C}=\mathrm{O}}$. Moreover, the area of $\mathrm{C}-\mathrm{O}-\mathrm{C}$, attributed to genipin, increases along with the ratio $A_{\mathrm{N}-\mathrm{H}} / A_{\mathrm{C}=\mathrm{O}}$ due to the carboxyl group from genipin. This fact is evidence of the crosslinking reaction. The higher decrease in the ratio $A_{\mathrm{N}-\mathrm{H}} /$ $A_{\mathrm{C}=\mathrm{O}}$ obtained for the blend systems is the combined effect of addition of elastin and genipin crosslinking.

The interaction between SF and elastin, crosslinked with genipin, was further investigated using thermal analysis (DSC). DSC scans for SF and elastin are shown in Fig. 2a and b respectively. The DSC curve for $100 \mathrm{SF}$ shows an endothermic shift at $184{ }^{\circ} \mathrm{C}$ that corresponds to the glass transition temperature $\left(T_{\mathrm{g}}\right)$ of $\mathrm{SF}$. This value is in the range of others previously reported for SF with a random coil conformation [39,57]. The exothermic peak at $226^{\circ} \mathrm{C}$ is related to the crystallization of amorphous SF chains caused by the transition to $\beta$-sheet structure $[52,56,58]$. The DSC curve of $\mathrm{SF}$ is also characterized by an intense endothermic peak at $284^{\circ} \mathrm{C}$ $\left(T_{\mathrm{d}}\right)$ related to the decomposition of SF chains.
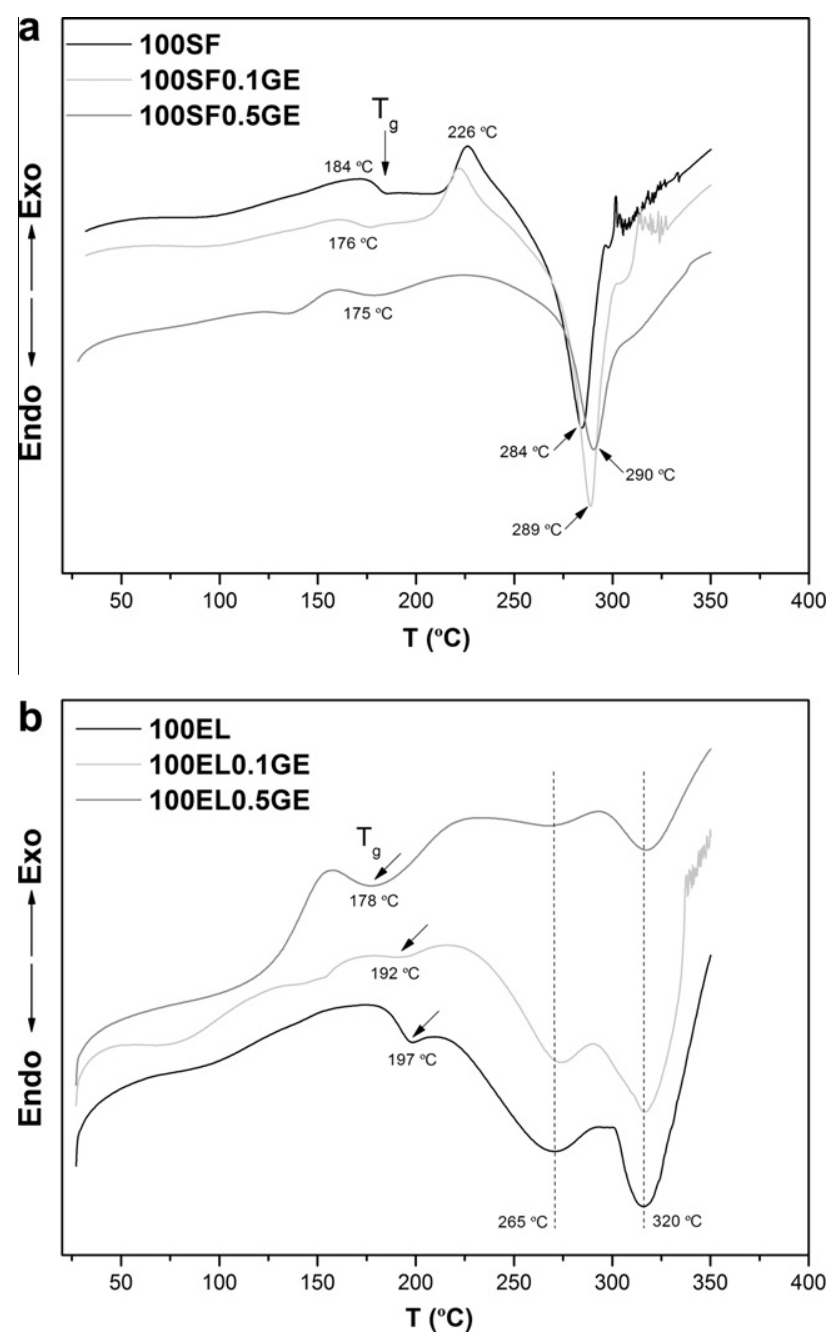

Fig. 2. DSC scans of (a) pure silk fibroin (100SF) and (b) pure elastin (100EL) and crosslinked with genipin (100X0.1GE and $100 \mathrm{X} 0.5 \mathrm{GE}$, where $\mathrm{X}$ is SF or EL).

The thermal behavior of 100SF is typical of an amorphous SF with random coil conformation as previously shown by FTIR results. Addition of genipin induces a small decrease in the $T_{\mathrm{g}}$ and an increase in the decomposition temperature. The increase in the thermal stability, given by the increase in $T_{\mathrm{d}}$, of $100 \mathrm{SF}$ scaffold containing genipin is due to the increase in the extent of covalent crosslinks. This fact is the confirmation of the crosslinking reaction between genipin and SF. Furthermore, the exothermic peak at $226{ }^{\circ} \mathrm{C}$ shifts to lower temperature (100SF0.1GE) and disappears for the sample 100SF0.5GE. This result shows once again the change in the SF conformation from random coil to $\beta$-sheet after genipin crosslinking, and how this change is affected by the concentration of crosslinking agent.

The DSC curve of elastin (Fig. 2b) shows an endothermic shift at $197{ }^{\circ} \mathrm{C}$ assigned to the glass transition temperature of soluble elastin peptides [59]. The thermogram is further characterized by a weak and broad endothermic peak at $265^{\circ} \mathrm{C}$, related to the decomposition of small aggregated structures and a more intense endothermic peak at $320^{\circ} \mathrm{C}$ related to a component decomposition at high temperature. Addition of genipin caused the decrease in the $T_{\mathrm{g}}$ and, although it was not observed, an increase in the decomposition temperature $\left(320^{\circ} \mathrm{C}\right)$; the weak peak at $265^{\circ} \mathrm{C}$ progressively disappears with the addition of genipin. This fact indicates that the small aggregates disappeared due to the crosslinking reaction between genipin and elastin. In the blend system (data not shown) 
an increase in the decomposition temperature is observed, suggesting once again the crosslinking effect. Nevertheless, the increase in $T_{\mathrm{d}}$ is not dependent on blend composition because blends with higher crosslinking degree will not have higher thermal stability.

The 3-D morphology of the SF/EL scaffolds was analyzed by SEM. The images presented are related to control and crosslinked scaffolds without methanol treatment. The 100SF sample (Fig. 3a) shows a disordered pore-like structure with a rough surface. The pores are interconnected by a number of even smaller pores. Addition of elastin creates a more open and loose structure with thinner walls (Fig. 3b and c). In the case of 50SF (Fig. 3c) a fibrilar structure can be observed. The presence of large pores in the scaffolds facilitates cellular infiltration and growth within the 3 -D structure $[16,60]$. However, such a loose network will have detrimental effects on mechanical, swelling and release properties. To overcome this, genipin crosslinking was performed and the results clearly evidenced that genipin changes the scaffold morphology. 100SF0.5GE scaffold (Fig. 3d) shows a more ordered pore structure interconnected between sheets, characteristic of a $\beta$-sheet conformation [58,61]. In addition, the SEM images obtained after methanol treatment (data not shown) show the same morphology observed with genipin crosslinking. This result shows the interaction between genipin and SF with conformational changes that are patent of the scaffold morphology already confirmed by FTIR and DSC results. In the blended system, it can be seen that the loose network obtained upon addition of elastin becomes more closed and compact due to genipin crosslinking. The fibrils observed in 50SF scaffold disappeared after crosslinking, originating thicker walls (Fig. $3 \mathrm{f}$ ).

Porosity measurement of scaffolds was done by the liquid displacement method, using hexane as a displacement liquid. Hexane was used because it permeates easily through the interconnected scaffold pores, causing negligible swelling or shrinkage. Porosity determination is important in tissue engineering as a highly porous structure provides much surface area that promotes better cell growth through the easer passage of nutrients to the growing cells. All the scaffolds, without genipin crosslinking, showed porosity ranging between 100 and 70\%, as shown in Fig. 3B. Addition of elastin increases the porosity of the scaffolds as can be seen by SEM analysis (Fig. 3A). Crosslinking with genipin significantly $(p<0.001)$ decreases the porosity of the SF/EL scaffolds, and the porosity increases accordingly to the elastin content in the scaffold.

Water-binding of scaffolds is an important parameter of biomaterials properties. To study the swelling ratio in response to external $\mathrm{pH}$ conditions, SF/EL scaffolds were immersed in PBS
A
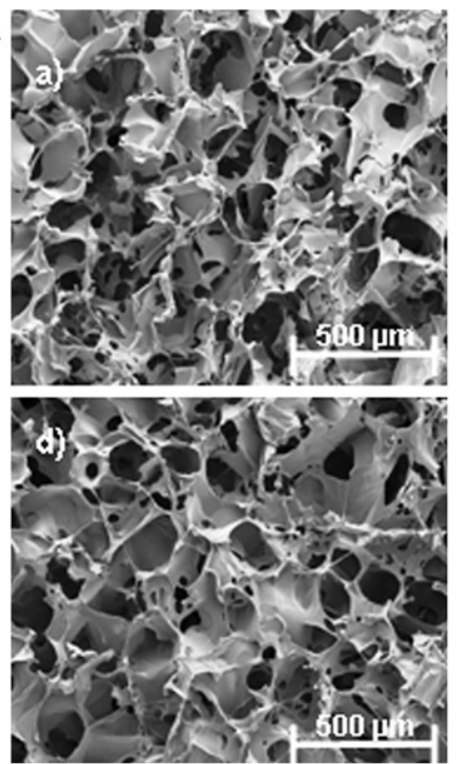
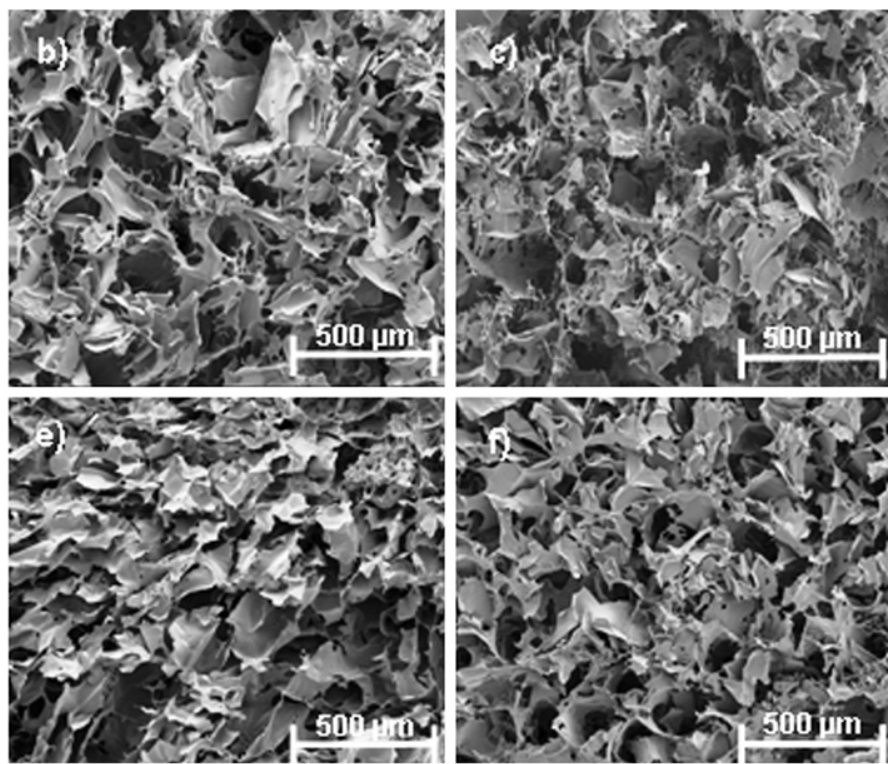

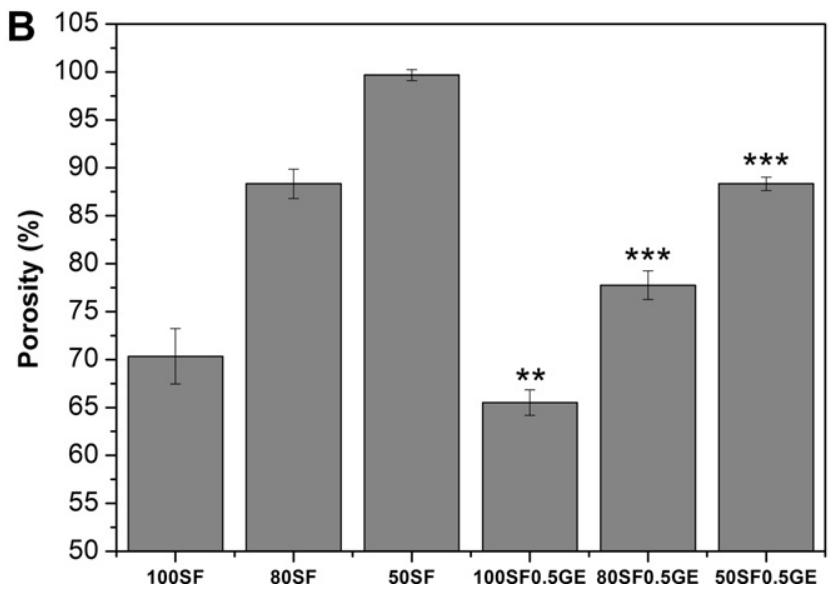

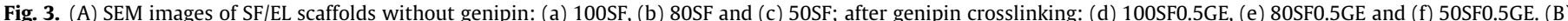

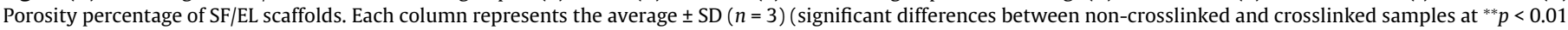
and $\left.{ }^{* * *} p<0.001\right)$. 
buffer solutions at $\mathrm{pH} 3,7.4$ and 11 for $24 \mathrm{~h}$ at $37^{\circ} \mathrm{C}$ and the results are presented in Fig. 4. The swelling ratio of SF/EL scaffolds was lower in acidic conditions and became progressively higher at neutral and alkaline media. The lowest swelling ratio obtained at $\mathrm{pH} 3$ might be attributed to the formation of hydrogen bonds between $\mathrm{SF}$ and elastin due to the presence of carboxylic acid groups $(-\mathrm{COOH})$ and hydroxyl groups $(-\mathrm{OH})$. Increasing the $\mathrm{pH}$, the carboxylic acid groups became ionized $\left(-\mathrm{COO}^{-}\right)$and consequently, higher swelling ratios are observed due to a higher swelling force induced by the electrostatic repulsion between the ionized acid groups.

The swelling ratio was found to be dependent on the composition; 50SF scaffolds, with and without genipin, showed maximums swelling ratios (Fig. 4). SEM analysis (Fig. 3c) indicates that 50SF samples presented larger pores with a loose network, still observed after crosslinking, which results in a higher hydrodynamic free volume to accommodate more of the solvent molecules, thus increasing scaffold swelling [62,63].

Crosslinking with genipin also affects the swelling ratio of the scaffolds. Increasing genipin concentration leads to a decrease in the swelling ratios. Generally, the swelling behavior of the scaffolds can be controlled by its composition and crosslinking degree. In the SF/EL scaffolds, genipin crosslinking created stable structures that hinder the mobility and relaxation of the macromolecular chains, lowering the swelling ratio due to water restrict mobility [64]. This effect is more pronounced in 80SF and 50SF scaffolds that attained higher crosslinking degrees when compared with 100SF. The decrease in the swelling ratio can also be correlated with the scaffold compact structures formed after crosslinking (Fig. 3d-f).

\subsection{In vitro and ex vivo biological degradation}

Degradation rate of matrices plays an essential role in the determination of the release of entrapped bioactive agents. The in vitro degradation of SF/EL scaffolds was investigated by incubation in a isotonic, physiological $\mathrm{pH}$ solution (PBS, $\mathrm{pH} 7.4$ ) and a protease rich medium (PPE and human exudate from chronic wounds) at $37^{\circ} \mathrm{C}$ for several days. At determined time points, samples were removed and washed with distilled water, dried and weighed to determine the extent of degradation using Eq. (4). The results are presented in Fig. 5. Scaffolds incubated with PBS solution showed almost no degradation within 21 days. From the results it can be seen that the degradation is dependent on scaffold composition. Higher weight loss was obtained for samples containing higher amounts of elastin. After 21 days of incubation, the weight loss obtained for 100SF, 80SF and 50SF in PPE solution was 26, 36 and $49 \%$ respectively. The low weight loss obtained for $100 \mathrm{SF}$ is related to the crystallinity of fibroin due to the presence of $\beta$-sheet structures. Therefore, the observed weight loss is probably due to the degradation of the small hydrolytically peptide sequences that remain after scaffold crystallization [65]. Nevertheless, this effect is minimized after genipin crosslinking that increases the $\beta$-sheet content, creating a closed and compact scaffold network (Fig. 3d). This will diminish the diffusion of solution within the scaffold, increasing the resistance to protease degradation. The higher
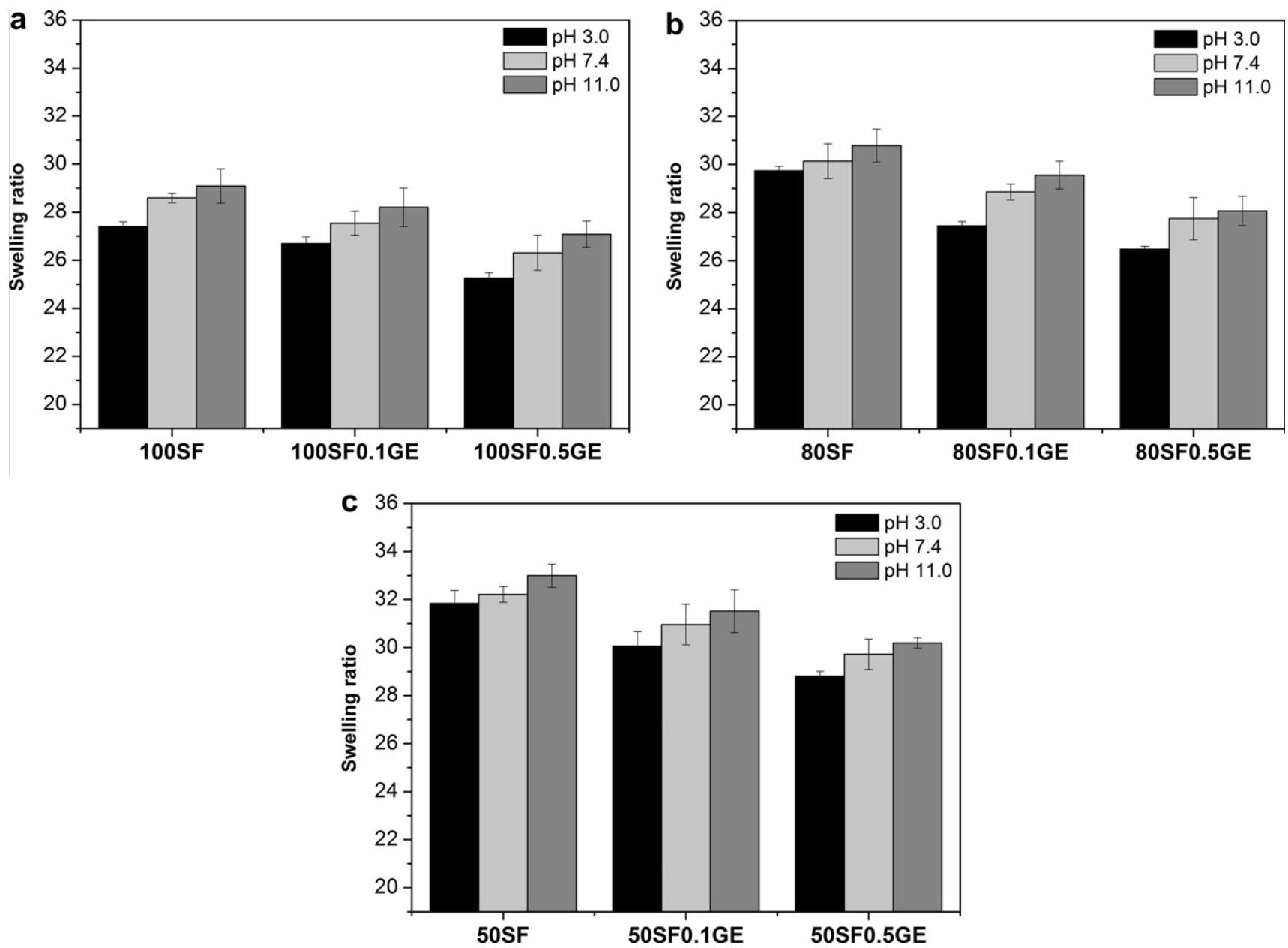

Fig. 4. The pH-dependent swelling ration of $100 \mathrm{SF}$ (a) $80 \mathrm{SF}$, (b) and $50 \mathrm{SF}$ (c) scaffolds after $24 \mathrm{~h}$ of immersion in buffer solutions at $37{ }^{\circ} \mathrm{C}$ determined by Eq. (2). 


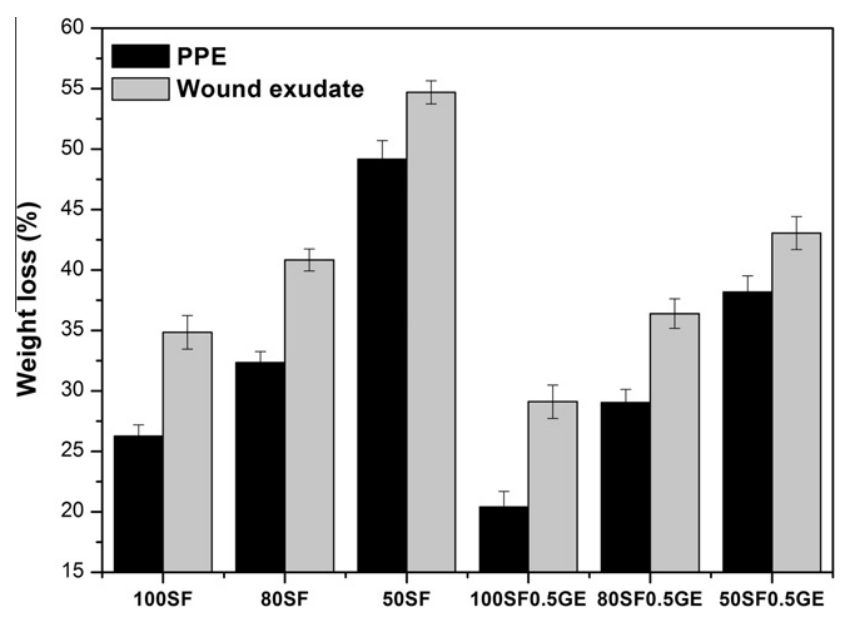

Fig. 5. In vitro degradation of SF/EL scaffolds incubated with $0.1 \mathrm{mg} \mathrm{ml}^{-1}$ of PPE and wound exudate $\left(2.4 \mu \mathrm{g} \mathrm{ml}^{-1}\right.$ of total protein content) at $37^{\circ} \mathrm{C}$ for 21 days.

weight loss obtained with scaffolds containing elastin is because elastin is a substrate for elastase. In the human body, elastin, one of the major components of connective tissues, is degraded by human leukocyte elastase (HLE) [66-68]. In this way, SF/EL scaffolds might be used as elastase-specific wound dressings for chronic wounds. Moreover, it has already been demonstrated that elastin-based dressings promote a better wound healing either by an improvement of fibroblasts adhesion and proliferation $[16,60]$ or by the reduction of wound contraction $[69,70]$.

The loose network observed for scaffolds containing elastin (Fig. 3c) is also responsible for the higher weight loss obtained due to the increase in the surface area. As observed before, the genipin crosslinking decreases the weight loss observed. The creation of a more compact structure between SF and elastin hinders scaffolds degradation. These results show that genipin crosslinking was effective in the control of degradation.

The results obtained with wound exudate show the same degradation pattern but with higher values. The exudate solution used for incubation was less concentrated than PPE solution $\left(2.4 \mu \mathrm{g} \mathrm{ml}^{-1}\right.$ of total protein content). Nevertheless, the wound exudate is a mixture of several proteases, including HLE, that act synergistically, increasing the hydrolysis.

\subsection{In vitro release}

The effect of scaffold composition and genipin crosslinking on the release of model compounds was investigated. The release behavior of gentamicin from SF/EL scaffolds in PPE solution is shown in Fig. 6. The release of this compound was monitored in PBS solution (data not shown) and the release observed was low. Gentamicin has been used topically in the treatment of superficial infections of the skin since it is effective against many aerobic Gram-negative and some aerobic Gram-positive bacteria. In this way, the antibacterial properties of SF/EL scaffolds will also be exploited. The release profile shown can be divided into three parts: an initial burst release in the initial $24 \mathrm{~h}$, due to the release of the compound bound to the surface of the scaffold; a continuous phase release from 24 to $72 \mathrm{~h}$; and a stagnant phase release for the remaining period of time. Furthermore, it was observed that higher release was obtained for scaffolds containing higher amounts of elastin. The release of a compound from a matrix is governed by several factors such as nature and size of the compound, degree and density of crosslinking and pore size among others. From the SEM results discussed previously, it was concluded that higher elastin content leads to scaffolds with higher pore size which in

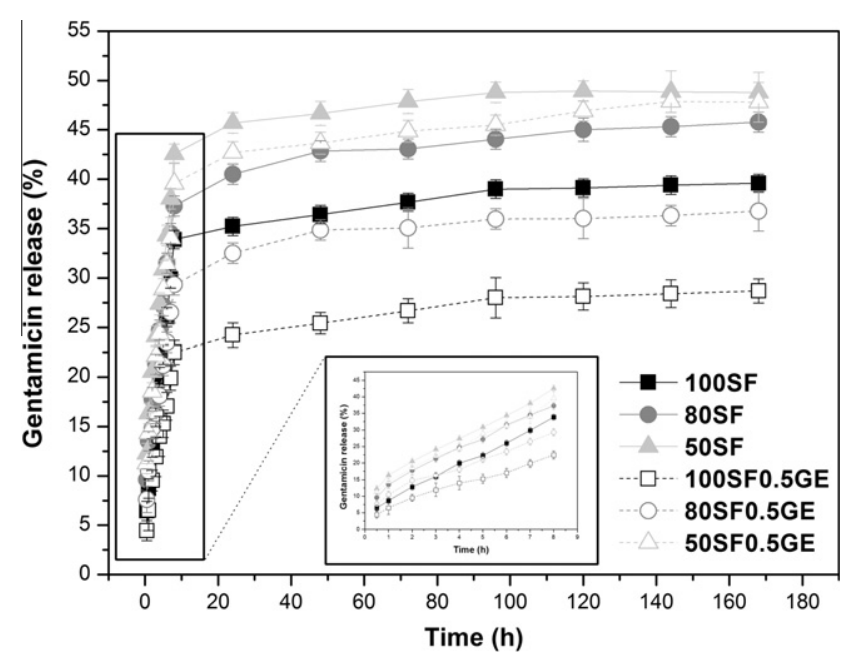

Fig. 6. Cumulative release of gentamicin from SF/EL scaffolds incubated with $0.1 \mathrm{mg} \mathrm{ml}^{-1}$ of PPE at $37^{\circ} \mathrm{C}$ for 21 days.

Table 2

Model compound release kinetic data obtained from fitting the experimental release data to Eq. (6).

\begin{tabular}{llll}
\hline Sample & \multicolumn{2}{l}{ Kinetic parameters } & $R^{2}$ \\
\cline { 2 - 4 } & $n$ & $k$ & 0.991 \\
\hline 100SF & 0.579 & 0.954 & 0.994 \\
80SF & 0.471 & 1.119 & 0.991 \\
100SF & 0.415 & 1.204 & 0.998 \\
80SF0.5GE & 0.551 & 0.813 & 0.990 \\
50SF0.5GE & 0.451 & 1.016 & 0.990 \\
\hline
\end{tabular}

turn cause the release of higher amounts of compounds. Genipin crosslinking induces slower release rates (Fig. 6). This is attributed to the fact that genipin crosslinking enhances the decrease of pore size. In this way, the diffusion of the compounds through the scaffold pores is more difficult and lower release is attained.

To determine the release mechanism present in the SF/EL scaffolds, the experimental data were fitted to the semi-empirical power law model [71,72] given by the Ritger-Peppas equation (Eq. (5)). This equation is further modified to determine the diffusional exponent, $n$ (Eq. (6)) that depends on the release mechanism and the geometry of the matrix $[45,71]$. There are three different mechanisms that can be concluded from the $n$ value. Therefore, the release, from a cylindrical geometry like the sponges developed, is purely Fickian diffusion when $n=0.45$; for $0.45<n>0.89$ anomalous (non-Fickian) transport is present and, for $n=0.89$ the release is dominated by Case II transport (matrix relaxation or swelling-controlled mechanism).

The results in Table 2, for control samples without crosslinking, showed that the release of gentamicin is dominated by anomalous transport because $n$ values are above and below 0.45 . In the blends, increasing elastin content, the values for release rate, $k$, became progressively higher. This indicates that the addition of elastin improves the release of drugs from the scaffolds probably due to the increase in swelling ratio and degradation rate, for higher elastin content as previously discussed. On the other hand, the decrease in the values for diffusional exponent, $n$, closest to 0.45 , suggests that the addition of elastin also improves the diffusion of drugs from the scaffolds.

Addition of genipin gradually changes the mechanism from anomalous transport to Fickian diffusion, especially for the sample 80SF0.5GE $(n=0.451)$. Furthermore, the crosslinking effect on the 


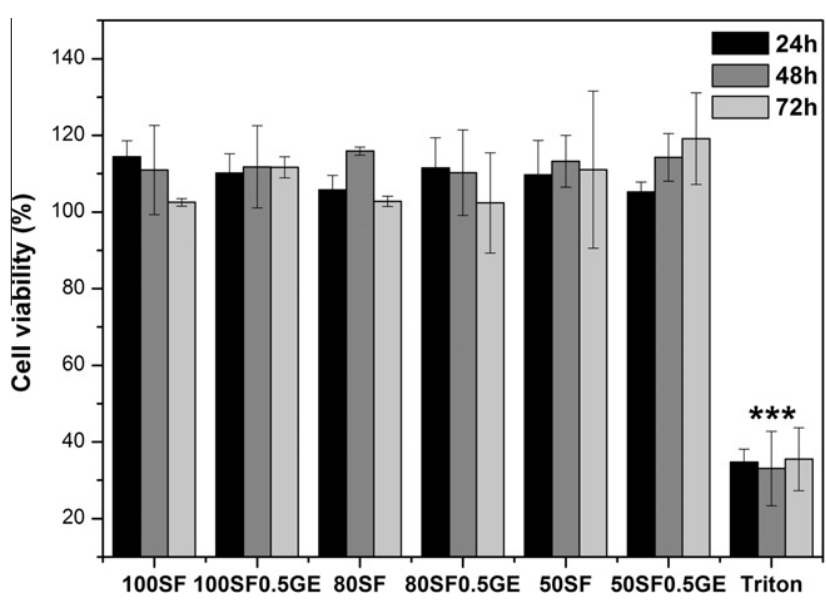

Fig. 7. Viability of human normal skin fibroblasts after $24 \mathrm{~h}, 48 \mathrm{~h}$ and $72 \mathrm{~h}$ of contact with conditioned medium (culture medium where scaffolds were incubated). Only the positive control (treatment with Triton detergent) revealed diminished cell viability. $\left(^{* * *}=\right.$ significantly different from all the other tested conditions, $p<0.001$ ).

scaffold morphology (compact and closed structure with smaller pores) also influences the release rate. It is observed that the release rate becomes slower (lower $k$ values) for higher amounts of elastin, due to the higher crosslinking degree obtained for these samples as explained before. The release results clearly support the notion that the release from SF/EL scaffolds is affected by its composition and that genipin crosslinking can be used to modulate the release mechanism and rate of the compounds.

\subsection{Cytocompatibility SF/EL scaffolds}

Biocompatibility of SF/EL scaffolds, with and without genipin crosslinking, was assessed in human skin fibroblasts in in vitro cultures. The results of the indirect contact study after fibroblast incubation with material extracts showed no cytotoxicity caused by medium conditioned by the scaffolds regardless of the incubation time. Fig. 7 represents the viability results for cells in contact with undiluted conditioned media. In all cases, the metabolic activity of cells in contact with the conditioned media was statistically similar or higher than the one obtained with negative control (complete culture medium). This result constitutes a preliminary study of the biocompatibility of SF/EL sponges, indicating that these materials are not cytotoxic.

Direct contact study was performed by seeding the cells on the scaffolds to evaluate the effect of SF/EL scaffolds on fibroblasts proliferation. The results presented in Fig. 8 showed a time-dependent increase in the number of cells that may suggest an increase in cell proliferation. Human skin fibroblasts continued to increase in number over the period examined, indicating that the scaffolds are able to support fibroblasts proliferation without producing toxic effects. It can also be observed that the presence of elastin on the scaffolds favors cell proliferation. Especially after 5 days of incubation. This fact is explained by the increase of hydrophilicity introduced by the presence of elastin that enhances cell adhesion and subsequent activity. For scaffolds crosslinked with genipin a decrease in the number of cells is observed when compared to non-crosslinked scaffolds, which might be related with the decrease in the porosity caused by the genipin crosslinking that inhibits cell infiltration.

Preliminary studies on the immunogenicity of SF/EL scaffolds were performed in vitro by measuring $\mathrm{TNF} \alpha$ production by THP-1 human macrophages exposed to these materials (data not shown). The results suggested that SF/EL scaffolds induce

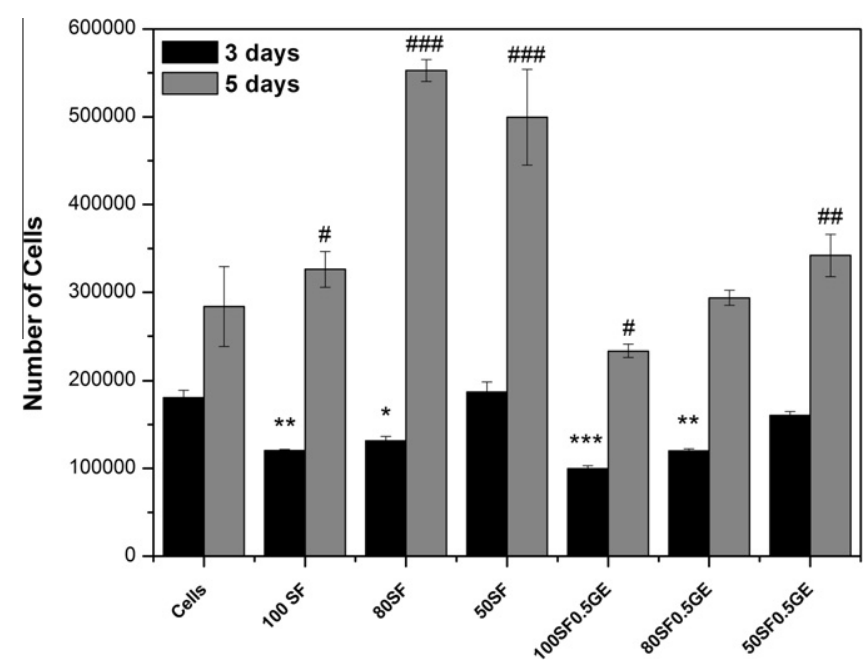

Fig. 8. Number of human normal skin fibroblasts cells, determined in terms of DNA content, after 3 and 5 days of direct contact (significantly different from cells control after 3 days of incubation at ${ }^{*} p<0.05$, ${ }^{* *} p<0.01$ and ${ }^{* * *} p<0.001$; significantly different from cells control after 5 days of incubation at ${ }^{\#} p<0.05$, ${ }^{\# \#} p<0.01$ and $\left.{ }^{\# \# \#} p<0.001\right)$.

production of low levels of the inflammatory mediator TNF $\alpha$ by these cells after $48 \mathrm{~h}$ of incubation when compared to PMA (phorbol 12-myristate-13 acetate), which is known to differentiate THP-1 cells into macrophage-like cells and mimic the intrinsic activation and differentiation signals that macrophages encounter during the foreign body reaction [73]. This additional observation further supports the notion that SF/EL scaffolds are non-immunogenic and represent a safe alternative biomaterial for the treatment of wounds.

\subsection{Wound healing}

To determine the effect of SF/EL scaffolds on the wound healing, materials were applied on the top of the wound immediately after causing the burn. Histological evaluation (Fig. 9) of the healing process after a period of 6 days revealed that SF/EL scaffolds induced fibroblasts and keratinocytes proliferation and migration to the wound site, especially for wounds treated with scaffolds containing elastin (Fig. 9a and b). The healing improvement obtained with SF/EL scaffolds is similar to the commercial collagen dressing, Suprasorb C, used in several types of wounds including burn wounds.

Microscopic observations of the wounds indicated that the control sample (Fig. 9a) is characterized by the absence of epithelium and the dermis is covered with crust from burning. After 6 days of healing, the crust had disappeared from the control sample (Fig. 9b) and from samples treated with different materials. In addition, wounds treated with dressings (collagen and SF/EL scaffolds) induced keratinocyte and fibroblast migration from the margins to the wound ground, which should result in a faster reepithelialization and wound closure. Partial-thickness burn wounds heal almost entirely by epithelialization from the skin periphery to the wound core [74,75], which was also observed in this study. For this reason, histological examination was done with sections obtained in the center of the wound, so the results presented and the differences obtained are related with the healing improvement by SF/EL scaffolds and not by natural artifacts. From the histological results obtained it is also visible that wounds treated with scaffolds containing higher amounts of elastin (50SF; Fig. 9f) are almost completely closed and covered with new epithelium, which was not the case in controls. The results indicated that 

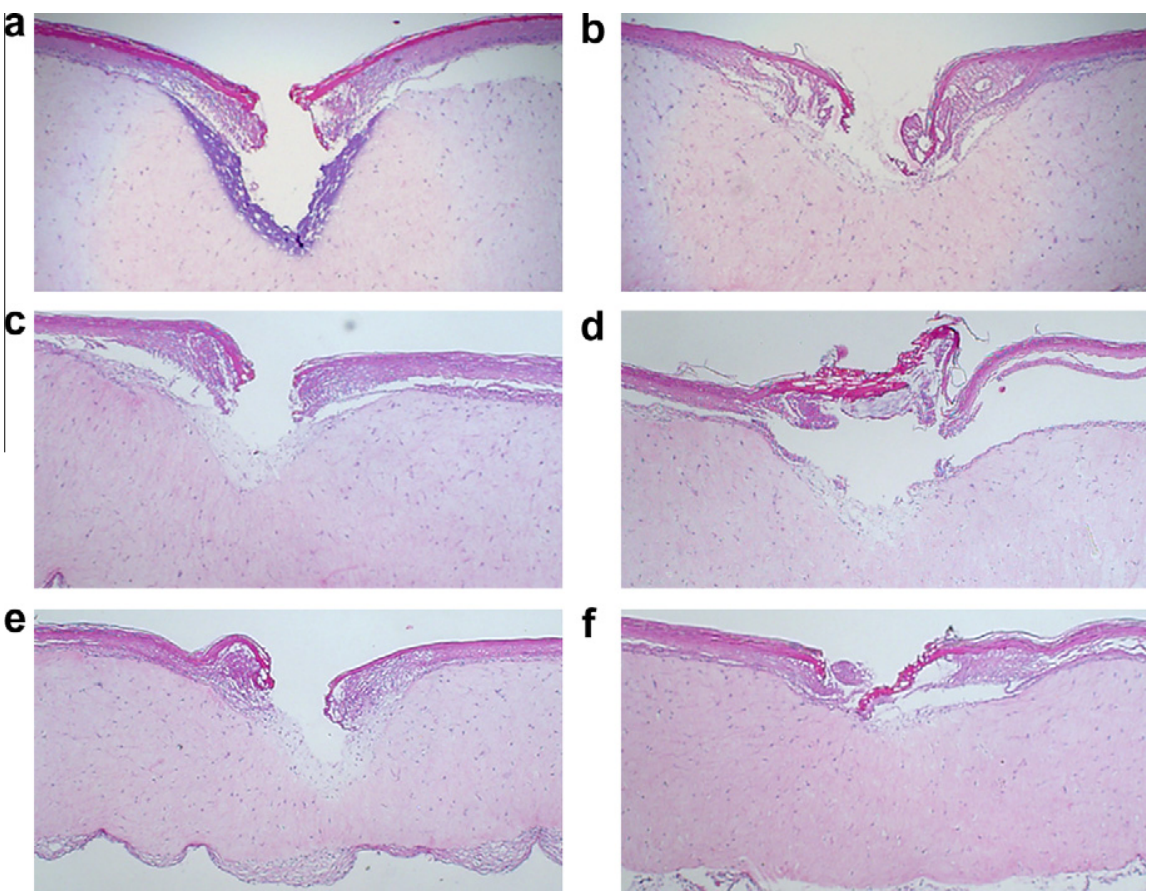

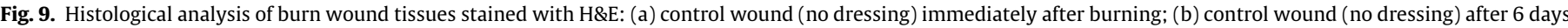

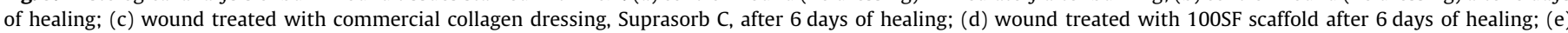
wound treated with 80SF scaffold after 6 days of healing; (f) wound treated with 50SF scaffold after 6 days of healing. Bars $=100 \mu \mathrm{m}$.

wound size reduction was significantly greater in the order of $50 \mathrm{SF}>80 \mathrm{SF}>100 \mathrm{SF}=$ Suprasorb $\mathrm{C}>$ No dressing.

The characterization results presented earlier indicated that scaffolds containing higher amounts of elastin become more swellable, flexible and elastic. These characteristics suggest that the attachment of the cells within the wound to the dressing is improved, resulting in a faster re-epithelialization.

Elastin is the major constituent of skin elastic fibers and is beneficial for dermal regeneration [76]. Several studies have explored the application of elastin containing materials for wound healing, such as scaffolds of collagen and solubilized elastin [77] or dermal substitutes coated with elastin [69,78]. Silk fibroin based-biomaterials have also been used in this field with promising results $[7,8,10]$; nevertheless, the present study exploits for the first time the combination of silk fibroin and elastin for the production of wound dressing scaffolds.

\section{Conclusion}

Novel SF/EL scaffolds crosslinked with genipin were successfully obtained. The genipin crosslinking results in the conformational transition of SF chains from random coil to $\beta$-sheet conformation. The SF/EL scaffolds presented different pore sizes and distinct morphologies which are related with the elastin ratio and genipin crosslinking. The biochemical and biophysical properties of the scaffolds such as higher thermal stability, pH-swelling dependence and reduced biological degradation and drug release rates were obtained after genipin crosslinking with a concentration of $0.5 \%$. A very important technical approach of this study was the validation of SF/EL scaffolds using human wound exudates. Degradation was evaluated using wound exudates, and it was observed that genipin crosslinking reduces susceptibility to degradation in this particular context. Moreover, SF/EL scaffolds showed no cytotoxicity and are able to support cell proliferation in vitro in human skin fibroblasts. Dermal burn healing experiments using human skin equivalents have shown that the application of SF/EL scaffolds containing higher amount of elastin accelerates re-epithelialization and wound closure. The results presented are important in the design and application of tailor-made biomaterials for wound dressings.

\section{Acknowledgements}

We would like to acknowledge FCT - Portuguese Foundation for Science and Technology for the scholarship conceded to Andreia Vasconcelos; European FP6 project Lidwine, contract no. NMP2CT-2006-026741 and PEst-C/BIA/UI4050/2011.

\section{Appendix A. Figures with essential colour discrimination}

Certain figures in this article, particularly Fig. 9, are difficult to interpret in black and white. The full colour images can be found in the on-line version, at http://dx.doi.org/10.1016/j.actbio.2012. 04.035 .

\section{References}

[1] Lazarus GS, Cooper DM, Knighton DR, Margolis DJ, Percoraro RE, Rodeheaver G et al. Definitions and guidelines for assessment of wounds and evaluation of healing. Wound Repair Regen 1994;2:165-70.

[2] Robson MC. Wound infection: a failure of wound healing caused by an imbalance of bacteria. Clin N Am 1997;77:637-50.

[3] Stadelmann WK, Digenis AG, Tobin GR. Physiology and healing dynamics of chronic cutaneous wounds. AM J SUR 1998;176:26S-38S.

[4] Harding KG, Morris HL, Patel GK. Healing chronic wounds. BM] 2002;324:160-3.

[5] Park JE, Barbul A. Understanding the role of imune regulation in wound healing. AM J SUR 2004;187:S11-6.

[6] Wharram SE, Zhang X, Kaplan DL, McCarthy SP. Electrospun silk materia systems for wound healing. Macromol Biosci 2010;10:246-57.

[7] Schneider A, Wang XY, Kaplan DL, Garlick JA, Egles C. Biofunctionalized electrospun silk mats as a topical bioactive dressing for accelerated wound healing. Acta Biomater 2009;5:2570-8.

[8] Sugihara A, Sugiura K, Morita H, Ninagawa T, Tubouchi K, Tobe R, et al. Promotive effects of a silk film on epidermal recovery from full-thickness skin wounds. Proc Soc Exp Biol Med 2000;225:58-64 
[9] Vasconcelos A, Pêgo AP, Henriques L, Lamghari M, Cavaco-Paulo A. Protein matrices for improved wound healing: elastase inhibition by a synthetic peptide model. Biomacromolecules 2010;11:2213-20.

[10] Roh D-H, Kang S-Y, Kim J-Y, Kwon Y-B, Young Kweon H, Lee K-G, et al. Wound healing effect of silk fibroin/alginate-blended sponge in full thickness skin defect of rat. J Mater Sci Mater Med 2006;17:547-52.

[11] Pasquali-Ronchetti I, Baccarani-Contri M. Elastic fiber during development and aging. Microsc Res Tech 1997;38:428-35.

[12] Faury G. Function-structure relationship of elastic arteries in evolution: from microfibrils to elastin and elastic fibres. Pathol Biol 2001;49:310-25.

[13] Martyn C, Greenwald S. A hypothesis about a mechanism for the programming of blood pressure and vascular disease in early life. Clin Exp Pharmacol Physiol 2001;28:948-51.

[14] Mithieux SM, Rasko JEJ, Weiss ASAS. Synthetic elastin hydrogels derived from massive elastic assemblies of self-organized human protein monomers. Biomaterials 2004;25:4921-7.

[15] Leach JB, Wolinsky JB, Stone PJ, Wong JY. Crosslinked [alpha]-elastin biomaterials: towards a processable elastin mimetic scaffold. Acta Biomater 2005;1:155-64.

[16] Annabi N, Mithieux SM, Weiss AS, Dehghani F. The fabrication of elastin-based hydrogels using high pressure $\mathrm{CO}_{2}$. Biomaterials 2009;30:1-7.

17] Urry DW, Chi-Hao L, Parker TM, Gowda DC, Prasad KU, Reid MC, et al. Temperature of polypeptide inverse temperature transition depends on mean residue hydrophobicity. J Am Chem Soc 1991;113:4346-8.

[18] Urry DW. Free energy transduction in polypeptides and proteins based on inverse temperature transitions. Prog Biophys Mol Biol 1992;57:23-57.

[19] Urry DW. Physical chemistry of biological free energy transduction as demonstrated by elastic protein-based polymers. J Phys Chem B 1997; 101:11007-28.

[20] Vieth S, Bellingham CM, Keeley FW, Hodge SM, Rousseau D. Microstructural and tensile properties of elastin-based polypeptides crosslinked with genipin and pyrroloquinoline quinone. Biopolymers 2007;85:199-206.

[21] McHale MK, Setton LA, Chilkoti A. Synthesis and in vitro evaluation of enzymatically cross-linked elastin-like polypeptide gels for cartilaginous tissue repair. Tissue Eng 2005;11:1768-79.

[22] Nagapudi K, Brinkman WT, Leisen J, Thomas BS, Wright ER, Haller C, et al Protein-based thermoplastic elastomers. Macromolecules 2004;38:345-54.

[23] Nagapudi K, Brinkman WT, Thomas BS, Park JO, Srinivasarao M, Wright E, et al. Viscoelastic and mechanical behavior of recombinant protein elastomers. Biomaterials 2005;26:4695-706.

[24] Mithieux SM, Tu Y, Korkmaz E, Braet F, Weiss AS. In situ polymerization of tropoelastin in the absence of chemical cross-linking. Biomaterials 2009;30:431-5.

[25] Lee J, Macosko CW, Urry DW. Mechanical properties of cross-linked synthetic elastomeric polypentapeptides. Macromolecules 2001;34:5968-74.

[26] Sung HW, Huang DM, Chang WH, Huang RN, Hsu JC. Evaluation of gelatin hydrogel crosslinked with various crosslinking agents as bioadhesives: in vitro study. J Biomed Mater Res 1999;46:520-30.

[27] Chang Y, Tsai C-C, Liang H-C, Sung H-W. In vivo evaluation of cellular and acellular bovine pericardia fixed with a naturally occurring crosslinking agen (genipin). Biomaterials 2002;23:2447-57.

[28] Fujikawa S, Nakamura S, Koga K. Genipin, a new type of protein crosslinking reagent from gardenia fruits. Agric Biol Chem 1988;52:869-70.

[29] Sung HW, Huang RN, Huang LLH, Tsai CC, Chiu CT. Feasibility study of a natura crosslinking reagent for biological tissue fixation. J Biomed Mater Res 1998;42:560-7.

[30] Sung HW, Liang IL, Chen CN, Huang RN, Liang HF. Stability of a biological tissue fixed with a naturally occurring crosslinking agent (genipin). J Biomed Mater Res 2001;55:538-46.

[31] Butler MF, Ng YF, Pudney PDA. Mechanism and kinetics of the crosslinking reaction between biopolymers containing primary amine groups and genipin. Polym Sci, Part A: Polym Chem 2003;41:3941-53.

[32] Chen H, Ouyang W, Lawuyi B, Martoni C, Prakash S. Reaction of chitosan with genipin and its fluorogenic attributes for potential microcapsule membrane characterization. J Biomed Mater Res A 2005;75A:917-27.

[33] Chang Y, Tsai C-C, Liang H-C, Sung H-W. Reconstruction of the right ventricular outflow tract with a bovine jugular vein graft fixed with a naturally occurring crosslinking agent (genipin) in a canine model. J Thorac Cardiovasc Surg 2001;122:1208-18.

[34] Li M, Mondrinos MJ, Gandhi MR, Ko FK, Weiss AS, Lelkes PI. Electrospun protein fibers as matrices for tissue engineering. Biomaterials 2005;26:5999-6008.

[35] Buttafoco L, Kolkman NG, Engbers-Buijtenhuijs P, Poot AA, Dijkstra PJ, Vermes $\mathrm{I}$, et al. Electrospinning of collagen and elastin for tissue engineering applications. Biomaterials 2006;27:724-34.

[36] Bonzon N, Carrat X, Deminière C, Daculsi G, Lefebvre F, Rabaud M. New artificial connective matrix made of fibrin monomers, elastin peptides and type I + III collagens: structural study, biocompatibility and use as tympanic membranes in rabbit. Biomaterials 1995;16:881-5.

[37] San-Galli F, Deminière G, Guérin J, Rabaud M. Use of a biodegradable elastinfibrin material, Neuroplast ${ }^{\circledR}$, as a dural substitute. Biomaterials 1996;17:1081-5.

[38] Li M, Mondrinos MJ, Chen X, Gandhi MR, Ko FK, Lelkes PI. Co-electrospun poly(lactide-co-glycolide), gelatin, and elastin blends for tissue engineering scaffolds. J Biomed Mater Res A 2006;79A:963-73.
[39] Vasconcelos A, Freddi G, Cavaco-Paulo A. Biodegradable materials based on silk fibroin and keratin. Biomacromolecules 2009:10:1019.

[40] Friedman M. Applications of the ninhydrin reaction for analysis of amino acids, peptides, and proteins to agricultural and biomedical sciences. J Agric Food Chem 2004;52:385-406.

[41] Yuan Y, Chesnutt BM, Utturkar G, Haggard WO, Yang Y, Ong JL, et al. The effect of cross-linking of chitosan microspheres with genipin on protein release. Carbohydr Polym 2007;68:561-7.

[42] Silva SS, Motta A, Rodrigues M, Pinheiro AFM, Gomes ME, Mano JF, et al. Novel genipin-cross-linked chitosan/silk fibroin sponges for cartilage engineering strategies. Biomacromolecules 2008;9:2764-74.

[43] Nazarov R, Jin H-J, Kaplan DL. Porous 3-D scaffolds from regenerated silk fibroin. Biomacromolecules 2004;5:718-26.

[44] Sampath SS, Robinson DH. Comparison of new and existing spectrophotometric methods for the analysis of tobramycin and other aminoglycosides. J Pharm Sci 1990;79:428-31.

[45] Ritger PL, Peppas NA. A simple equation for description of solute release II. Fickian and anomalous release from swellable devices. J Controlled Release 1987;5:37-42.

[46] Mi FL, Sung HW, Shyu SS. Synthesis and characterization of a novel chitosanbased network prepared using naturally occurring crosslinker. J Polym Sci, Part A: Polym Chem 2000;38:2804-14.

[47] Sung HW, Chang Y, Liang IL, Chang WH, Chen YC. Fixation of biological tissues with a naturally occurring crosslinking agent: fixation rate and effects of $\mathrm{pH}$, temperature, and initial fixative concentration. J Biomed Mater Res 2000;52:77-87.

[48] Liang HC, Chang WH, Liang HF, Lee MH, Sung HW. Crosslinking structures of gelatin hydrogels crosslinked with genipin or a water-soluble carbodiimide. J Appl Polym Sci 2004;91:4017-26.

[49] Silva SS, Maniglio D, Motta A, Mano JF, Reis RL, Migliaresi C. Genipin-modified silk-fibroin nanometric nets. Macromol Biosci 2008;8:766-74.

[50] Chen X, Knight DP, Shao Z, Vollrath F. Regenerated Bombyx silk solutions studied with rheometry and FTIR. Polymer 2001;42:9969-74.

[51] Chen X, Shao Z, Marinkovic NS, Miller LM, Zhou P, Chance MR. Conformation transition kinetics of regenerated Bombyx mori silk fibroin membrane monitored by time-resolved FTIR spectroscopy. Biophys Chem 2001;89:25-34.

[52] Hu X, Kaplan D, Cebe P. Determining beta-sheet crystallinity in fibrous proteins by thermal analysis and infrared spectroscopy. Macromolecules 2006;39:6161-70.

[53] Chen X, Shao Z, Knight DP, Vollrath F. Conformation transition kinetics of Bombyx mori silk protein. Protein: Struct, Funct, Bioinformatics 2007;68:22331.

[54] Wise SG, Mithieux SM, Weiss AS, Alexander M. Engineered tropoelastin and elastin-based biomaterials. Advances in Protein Chemistry and Structural Biology: Academic Press; 2009. p. 1-24.

[55] Wise SG, Weiss AS. Tropoelastin. Int J Biochem Cell Biol 2009;41:494-7.

[56] Hu X, Wang X, Rnjak J, Weiss AS, Kaplan DL. Biomaterials derived from silktropoelastin protein systems. Biomaterials 2010;31:8121-31.

[57] Karageorgiou V, Meinel L, Hofmann S, Malhotra A, Volloch V, Kaplan D. Bone morphogenetic protein-2 decorated silk fibroin films induce osteogenic differentiation of human bone marrow stromal cells. J Biomed Mater Res A 2004;71A:528-37.

[58] Lu Q, Zhang X, Hu X, Kaplan DL. Green process to prepare silk fibroin/gelatin biomaterial scaffolds. Macromol Biosci 2010;10:289-98.

[59] Samouillan V, André C, Dandurand J, Lacabanne C. Effect of water on the molecular mobility of elastin. Biomacromolecules 2004;5:958-64.

[60] Annabi N, Mithieux SM, Boughton EA, Ruys AJ, Weiss AS, Dehghani F. Synthesis of highly porous crosslinked elastin hydrogels and their interaction with fibroblasts in vitro. Biomaterials 2009;30:4550-7.

[61] She Z, Zhang B, Jin C, Feng Q, Xu Y. Preparation andin vitro degradation of porous three-dimensional silk fibroin/chitosan scaffold. Polym Degrad Stab 2008;93:1316-22

[62] Rokhade AP, Patil SA, Aminabhavi TM. Synthesis and characterization of semiinterpenetrating polymer network microspheres of acrylamide grafted dextran and chitosan for controlled release of acyclovir. Carbohydr Polym 2007;67:605-13.

[63] Mandal BB, Kapoor S, Kundu SC. Silk fibroin/polyacrylamide semiinterpenetrating network hydrogels for controlled drug release. Biomaterials 2009;30:2826-36.

[64] Bajpai AK, Giri A. Water sorption behaviour of highly swelling (carboxy methylcellulose-g-polyacrylamide) hydrogels and release of potassium nitrate as agrochemical. Carbohydr Polym 2003;53:271-9.

[65] Lu S, Wang X, Lu Q, Hu X, Uppal N, Omenetto FG, et al. Stabilization of enzymes in silk films. Biomacromolecules 2009;10:1032-42.

[66] Havemann K, Gramse M. Physiology and pathology of neutral proteinases of human granurocytes. Adv Exp Med Biol 1984;164:1-20.

[67] Owen CA, Campbell MA, Sannes PL, Boukedes SS, Campbell EJ. Cell surfacebound elastase and cathepsin $\mathrm{G}$ on human neutrophils: a novel, non-oxidative mechanism by which neutrophils focus and preserve catalytic activity of serine proteinases. J Cell Biol 1995;131:775-89.

[68] Siedle B, Gustavsson L, Johansson S, Murillo R, Castro V, Bohlin L, et al. The effect of sesquiterpene lactones on the release of human neutrophil elastase. Biochem Pharmacol 2003;65:897-903.

[69] Lamme EN, de Vries HJ, van Veen H, Gabbiani G, Westerhof W, Middelkoop E. Extracellular matrix characterization during healing of full-thickness wounds 
treated with a collagen/elastin dermal substitute shows improved skin regeneration in pigs. J Histochem Cytochem 1996;44:1311-22.

[70] Lamme EN, van Leeuwen RTJ, Jonker A, van Marle J, Middelkoop E. Living skin substitutes: survival and function of fibroblasts seeded in a dermal substitute in experimental wounds. J Invest Dermatol 1998;111:989-95.

[71] Ferrero C, Massuelle D, Doelker E. Towards elucidation of the drug release mechanism from compressed hydrophilic matrices made of cellulose ethers. II. Evaluation of a possible swelling-controlled drug release mechanism using dimensionless analysis. J Controlled Release 2010;141:223-33.

[72] Korsmeyer RW, Peppas NA. Effect of the morphology of hydrophilic polymeric matrices on the diffusion and release of water soluble drugs. J Membr Sci 1981;9:211-27.

[73] Thomsen P, Gretzer C. Macrophage interactions with modified material surfaces. Curr Opin Solid State Mater Sci 2001;5:163-76.
[74] Abramo AC, Viola JC. Heterologous collagen matrix sponge: histologic and clinical response to its implantation in third-degree burn injuries. Br J Plast Surg 1992;45:117-22.

[75] Mast BA, Schultz GS. Interactions of cytokines, growth factors, and proteases in acute and chronic wounds. Wound Repair Regen 1996;4:411-20.

[76] Daamen WF, Veerkamp JH, van Hest JCM, van Kuppevelt TH. Elastin as a biomaterial for tissue engineering. Biomaterials 2007;28:4378-98.

[77] Daamen WF, Nillesen STM, Wismans RG, Reinhardt DP, Hafmans T, Veerkamp $\mathrm{JH}$, et al. A biomaterial composed of collagen and solubilized elastin enhances angiogenesis and elastic fiber formation without calcification. Tissue Eng Part A 2008;14:349-60.

[78] Ryssel H, Gazyakan E, Germann G, Öhlbauer M. The use of MatriDerm ${ }^{\circledR}$ in early excision and simultaneous autologous skin grafting in burns - a pilot study. Burns 2008;34:93-7. 